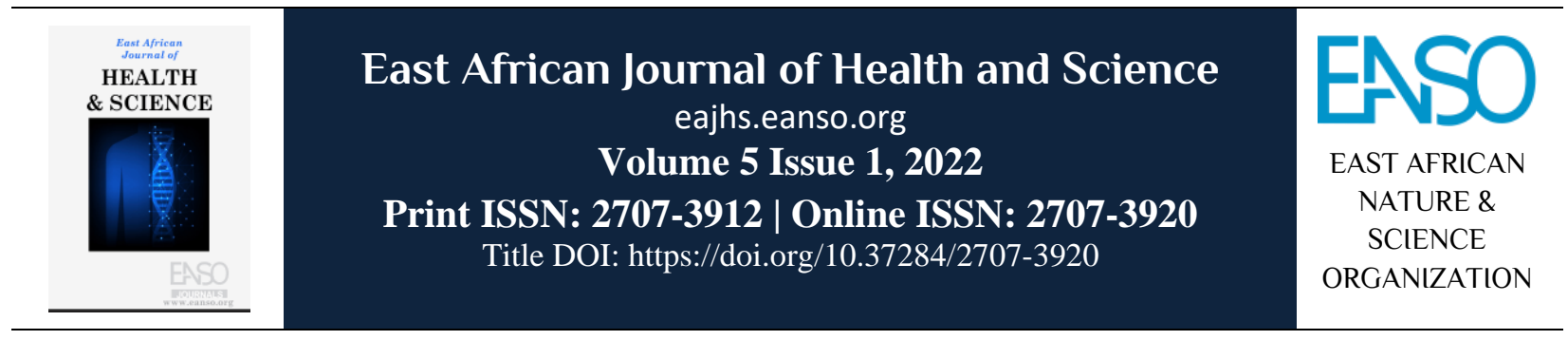

Original Article

\title{
Male Contraceptive Uptake and Associated Socio-Economic Characteristics in Kenya.
}

\author{
Anderson M. Mwito ${ }^{1}$, Dr. Lucy W. Ngige, PhD ${ }^{2 *} \&$ Dr. Jane N. Kieru, PhD ${ }^{2}$ \\ ${ }^{1}$ Jomo Kenyatta, P. O. Box 62000-00200, Nairobi, Kenya. \\ ${ }^{2}$ Kenyatta University, P. O. Box 43844-00100, Nairobi, Kenya. \\ *Author for correspondence ORCID ID: https://orcid.org/0000-0003-1750-1496; email: ngige.lucy@ku.ac.ke.
}

Article DOI: https://doi.org/10.37284/eajhs.5.1.536

\begin{abstract}
Date Published: ABSTRACT
25 January 2022 This research investigated the relationship between socioeconomic characteristics and male contraceptive uptake in Kenya. A survey of 572

Keywords: randomly selected male respondents participated in the study. The study assessed the respondents' socioeconomic profiles such as the location of Male Contraceptives, residence, age, marital status, polygyny, family size, education Condom, attainment, working status and income level. The age of the respondents Vasectomy, ranged from 18 to 60 years. Chi-square results indicated significant relationships between male contraceptive uptake and socioeconomic Natural Family Planning, characteristics such as location of residence $(p=0.005)$, age $(p=0.005)$,

Optimal Family Size. marital status $(\mathrm{p}=0.005)$, family size $(\mathrm{p}=0.021)$, education attainment $(\mathrm{p}$ $=0.005)$ and income level $(\mathrm{p}=0.032)$. The study concluded that men's area of residence, age, marital status, desired number of children, level of education and level of income had a significant influence on male contraceptive uptake. It is recommended that there is a need to develop male-friendly and acceptable contraceptive options for men besides condoms and vasectomy, with the view of increasing contraceptive uptake among males in Kenya.
\end{abstract}

\section{APA CITATION}

Mwito, A. M., Ngige, L. W. \& Kieru, J. N. (2022). Male Contraceptive Uptake and Associated Socio-Economic Characteristics in Kenya. East African Journal of Health and Science, 5(1), 26-35. https://doi.org/10.37284/eajhs.5.1.536.

\section{CHICAGO CITATION}

Mwito, Anderson M, Lucy W. Ngige, \& Jane N. Kieru. 2022. "Male Contraceptive Uptake and Associated Socio-Economic Characteristics in Kenya.". East African Journal of Health and Science 5 (1), 26-35. https://doi.org/10.37284/eajhs.5.1.536.

26 | This work is licensed under a Creative Commons Attribution 4.0 International License. 
HARVARD CITATION

Mwito, A. M., Ngige, L. W., \& Kieru, J. N. (2022) "Male Contraceptive Uptake and Associated Socio-Economic Characteristics in Kenya.", East African Journal of Health and Science, 5(1), pp. 26-35. doi: 10.37284/eajhs.5.1.536.

\section{IEEE CITATION}

A. M. Mwito, L. W. Ngige, \& J. N. Kieru, "Male Contraceptive Uptake and Associated Socio-Economic Characteristics in Kenya.”, EAJHS, vol. 5, no. 1, pp. 26-35, Jan. 2022.

\section{MLA CITATION}

Mwito, Anderson M, Lucy W. Ngige, \& Jane N. Kieru. "Male Contraceptive Uptake and Associated Socio-Economic Characteristics in Kenya.". East African Journal of Health and Science, Vol. 5, no. 1, Jan. 2022, pp. 26-35, doi:10.37284/eajhs.5.1.536.

\section{INTRODUCTION}

Contraception is a birth control method that can be used for family planning either in males or females to prevent conception. The decision on whether and what to use for family planning is critical in every family (Guttmacher Institute, 2021). Contraceptives are useful in preventing unwanted and unplanned pregnancies. Some contraception such as condoms may also be used to protect against Sexually Transmitted Infections (STIs) including Human Immuno-Deficiency Virus (HIV), gonorrhoea and syphilis (Matlala \& Mpolokeng, 2010). Family planning improves the health and socioeconomic conditions of families who adopt the practice. Contraceptives also help empower women and men to have control over their ability to have the desired number of children they are able to take care of. There is therefore need to understand and improve family planning uptake by both men and women in an effort to improve reproductive health in Kenya.

Globally, contraceptive prevalence is estimated at 63 per cent (United Nations, 2021). The report indicates that contraceptive prevalence among women of reproductive age varies between four per cent in South Sudan and 88 per cent in Norway. Among the least developed countries in the world, 36 per cent of women in the reproductive age use contraception compared to developed countries that have achieved 66 per cent contraceptive uptake. The level of unmet need for contraception in Asia is $10.9 \%$, while in Latin America is at $10.4 \%$ compared to Africa at $23.2 \%$ (United Nations, 2021). In Kenya, the Contraceptive Prevalence Rate (CPR) and Total Fertility Rate (TFR) among women aged 15-49 years old are 58\% and 3.9, respectively. Female contraceptive uptake is higher compared to male contraceptive uptake. According to the Kenya National Bureau of Statistics (2010), men have been reluctant to adopt male contraceptive methods and have also been an impediment to women using any form of family planning methods.

Traditionally, contraception has been and is seen as the responsibility of women. The World Health Organization (2020) stated that the use of contraception by men makes up a relatively small subset of the contraceptive prevalence options: condom, vasectomy or natural methods. There is a notable lack of reliable and reversible methods available to men. There is a big challenge in men's involvement in family planning which is to identify the strategy that will most effectively encourage the men to get involved (Shattuck et al., 2011). In Kenya, family planning is mainly used by women. In rural areas, birth is rarely controlled and most women get as many children as their fertility can allow (Kenya Demographic and Health Survey (KDHS) \& ICF Macro. (2014); Ngige, Ondigi \& Wilson, (2008). Furthermore, women look up to their male partners to decide on reproductive matters including the desired family size and whether a female partner may use contraception or not.

A study conducted by Odu et al. (2006) established that in Nigerian men's knowledge of and attitudes to family planning is still poor despite a global move to promote male participation in reproductive health matters. In Kenya, the majority of men have negative attitudes towards the uptake of contraceptives. This is attributed to cultural traditions and myths about reproduction and male libido. Therefore, there is scarce information on male contraceptive uptake in Kenya. The main objective of this research was to determine whether socioeconomic characteristics were significantly related to male contraceptive uptake. The null 
hypothesis stated that socioeconomic characteristics such as location of residence, age, marital status, polygyny, family size, education attainment, employment status and income level had no significant relationship with contraceptive uptake among male respondents.

\section{METHODS}

This research used a cross-sectional survey research design. A random sample of 572 male respondents aged between 18 to 60 years was selected from urban, peri-urban and rural households in Meru County, Kenya. Data was gathered by means of a structured questionnaire and analysed by use of the Statistical Package for the Social Sciences (SPSS) Version 24. In order to determine the independent variables, the socioeconomic characteristics were assessed by investigating variables such as the location of residence, age, marital status, polygyny, family size, education attainment, employment status and aggregate monthly income. The dependent variable was male contraceptive uptake in the year prior to the study. The reliability of the research instrument was measured by the split-half Cronbach's reliability test. The computed Cronbach's correlation coefficient was 0.78 which was considered acceptable according to Orodho (2008). The researchers adhered to the ethical standards as set by the relevant Ethics Review Committee and the National Council for Science Technology and Innovation.

\section{RESULTS}

The study investigated whether there existed a significant relationship between male contraceptive uptake and socioeconomic characteristics, namely location of residence, age, marital status, polygyny, family size, education attainment, employment status and income level. The research findings are presented in the section that follows.

\section{Male Contraceptive Uptake}

The distribution of respondents' contraceptive uptake is shown in Figure 1.

\section{Figure 1: Distribution of respondents by contraceptive uptake}

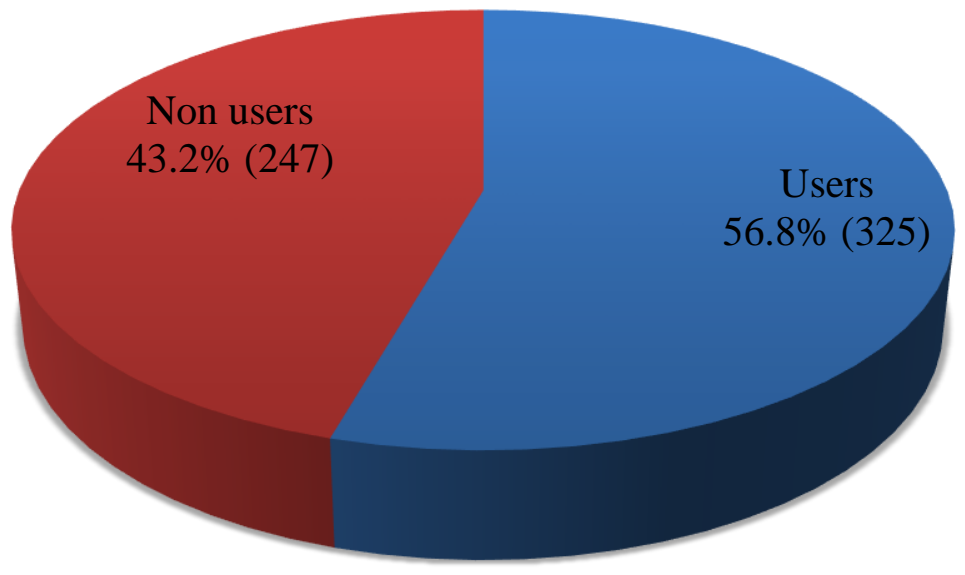

Research findings indicated that $56.8 \%$ were contraceptive users, while $43.2 \%$ were non-users. Of the contraceptive users $(n=325), 32.5 \%$ reported that they used condoms consistently, while $67.5 \%$ indicated that they used natural family planning methods and none had opted for vasectomy $(0.0 \%)$.
This implied that less than one-third of the male respondents used contraceptives. 


\section{Male Contraceptive Uptake by Location of Residence}

Hol: Contraceptive uptake is not significantly related to respondents' location of residence at $p \leq 0.05$.
The results of contraceptive uptake by respondents' location of residence are presented in Table 1.

Table 1: Chi-square results for contraceptive uptake by residence

\begin{tabular}{lllllllll}
\hline Contraceptive Uptake Status & \multicolumn{4}{l}{ Location of Residence $(\mathbf{n}=\mathbf{5 7 2})$} & \multicolumn{4}{c}{ Total } \\
\cline { 2 - 8 } & Urban & \multicolumn{1}{c}{ Sub-Urban } & \multicolumn{1}{c}{ Rural } & & \\
\hline Contraceptive Users & 131 & 40.3 & 115 & 35.4 & 79 & 24.3 & 325 & 56.8 \\
Contraceptive non-Users & 67 & 27.1 & 95 & 38.4 & 85 & 34.4 & 247 & 43.2 \\
Total & $\mathbf{1 9 8}$ & $\mathbf{3 4 . 6}$ & $\mathbf{2 1 0}$ & $\mathbf{3 6 . 7}$ & $\mathbf{1 6 4}$ & $\mathbf{2 8 . 7}$ & $\mathbf{5 7 2}$ & $\mathbf{1 0 0 . 0}$ \\
$(\chi 2=45.911 ; \mathrm{df}=3 ; p=0.005)$ & & & & & & & & \\
\hline
\end{tabular}

The results showed that urban respondents achieved higher contraceptive uptake $(40.3 \%)$ than their suburban $(35.4 \%)$ and rural counterparts $(24.3 \%)$. The Chi-square results $\left(\chi^{2}=45.911 ; d f=3 ; p=0.005\right)$ established there was a statistically significant relationship between contraceptive uptake among respondents by residential location at $\mathrm{p} \leq 0.05$. The null hypothesis was rejected and alternate retained. A conclusion was drawn that contraceptive uptake was significantly related to residential locations. These findings implied that the urban respondents achieved higher levels of contraceptive uptake than rural or suburban counterparts.

\section{Male Contraceptive Uptake by the Age of Respondents}

$\mathrm{Ho}_{2}$ : Contraceptive uptake is not significantly related to respondents' age at $p \leq 0.05$.

Chi-square test results for contraceptive uptake by age are presented in Table 2.

Table 2: Chi-square results for contraceptive uptake by Respondents' age

\begin{tabular}{|c|c|c|c|c|c|c|c|c|c|c|}
\hline \multirow[b]{3}{*}{ Contraceptive Uptake status } & \multicolumn{10}{|c|}{ Age of Respondents $(n=572)$} \\
\hline & \multicolumn{2}{|c|}{ Below 20} & \multicolumn{2}{|c|}{$21-30$} & \multicolumn{2}{|c|}{$31-40$} & \multicolumn{2}{|c|}{ 41+ } & \multicolumn{2}{|c|}{ Total } \\
\hline & $\mathbf{n}$ & $(\%)$ & $\mathbf{N}$ & $(\%)$ & n & $(\%)$ & $\mathbf{n}$ & $(\%)$ & $\mathbf{n}$ & $(\%)$ \\
\hline Contraceptive Users & 21 & 6.5 & 182 & 56 & 110 & 33.8 & 12 & 3.7 & 325 & 56.8 \\
\hline Contraceptive Non-Users & 34 & 13.8 & 111 & 44.9 & 68 & 27.5 & 34 & 13.8 & 247 & 43.2 \\
\hline $\begin{array}{l}\text { Total } \\
\chi^{2}=29.621, \mathrm{df}=4, \mathrm{p}=0.005\end{array}$ & 55 & 9.6 & 293 & 51.2 & 178 & 31.1 & 46 & 8 & 572 & 100 \\
\hline
\end{tabular}

The research findings indicated that $51.2 \%$ of respondents between 21-30 years had the highest contraceptive uptake followed by those aged 31-40 years $(31.1 \%)$, and then it tapers off to $8.0 \%$ for males over 41 years and $9.6 \%$ to for younger males aged 20 years and below. The Chi-square results $(\chi 2=29.621, \mathrm{df}=4, p=0.005)$ established that age was significantly related to male contraceptive uptake among respondents at $p \leq 0.05$. The null hypothesis was rejected and alternate retained. A conclusion was drawn that male contraceptive uptake was significantly related to the age of the respondents. These findings implied that middleaged males had higher levels of contraceptive uptake than younger and older counterparts.

\section{Male Contraceptive Uptake and Marital Status}

Hoз: Contraceptive uptake is not significantly related to marital status at $p \leq 0.05$.

The Chi-square tests results of respondents' contraceptive uptake by their marital status are presented in Table 3.

29 | This work is licensed under a Creative Commons Attribution 4.0 International License. 
East African Journal of Health and Science, Volume 5, Issue 1, 2022

Article DOI: https://doi.org/10.37284/eajhs.5.1.536

Table 3: Chi-square results for contraceptive uptake by marital status

\begin{tabular}{|c|c|c|c|c|c|c|c|c|}
\hline \multirow{3}{*}{$\begin{array}{l}\text { Contraceptive } \\
\text { Status }\end{array}$} & eMar & al sta & $1=57$ & & & & & \\
\hline & \multicolumn{2}{|c|}{ Married } & \multicolumn{2}{|c|}{ Single } & \multicolumn{2}{|c|}{ Divorced/Separated } & \multicolumn{2}{|c|}{ Total } \\
\hline & $\bar{n}$ & $(\%)$ & $\mathbf{n}$ & $(\%)$ & $\mathbf{n}$ & $(\%)$ & $\mathbf{n}$ & $(\%)$ \\
\hline Contraceptive Users & 293 & 90.2 & 24 & 7.4 & 8 & 2.4 & 325 & 56.8 \\
\hline Contraceptive non-Users & 77 & 31.2 & 166 & 67.2 & 4 & 1.6 & 247 & 43.2 \\
\hline $\begin{array}{l}\text { Total } \\
\chi 2=124.974, \mathrm{df}=3, p=0 .\end{array}$ & 370 & 64.7 & 190 & 33.2 & 12 & 2.1 & 572 & 100.0 \\
\hline
\end{tabular}

The results showed that the highest rate of contraceptive use was among the married respondents $(90.2 \%)$, while single males accounted for $7.4 \%$ and $2.4 \%$ of divorced or separated respondents. The Chi-square results $(\chi 2=124.974$, $\mathrm{df}=3, p=0.005)$ established that marital status was significantly related to male contraceptive uptake among respondents at $\mathrm{p} \leq 0.05$ ). The null hypothesis was rejected and alternate retained. A conclusion was drawn that male contraceptive uptake was significantly related to the marital status of the respondents. These findings implied that married men had a higher propensity of contraceptive uptake than single and divorced respondents.

\section{Contraceptive Uptake by Polygyny}

Ho4: Contraceptive uptake is not significantly related to polygyny status at $p \leq 0.05$.

Polygyny refers to the number of wives a man has. Chi-square results for contraceptive uptake by the number of wives a respondent had are indicated in Table 4.

Table 4: Chi-square results for contraceptive uptake by polygyny

\begin{tabular}{|c|c|c|c|c|c|c|}
\hline \multirow[t]{3}{*}{ Contraceptive uptake status } & \multicolumn{6}{|c|}{ Status of Polygyny $(n=370)$} \\
\hline & \multicolumn{2}{|c|}{ Monogamous Union } & \multicolumn{2}{|c|}{ Polygynous Union } & \multicolumn{2}{|c|}{ Total } \\
\hline & $\mathrm{n}$ & $(\%)$ & $\mathbf{N}$ & $(\%)$ & & $(\%)$ \\
\hline Contraceptive Users & 146 & 64.3 & 81 & 35.7 & 227 & 61.4 \\
\hline Contraceptive non-Users & 83 & 58.0 & 60 & 42.0 & 143 & 38.6 \\
\hline $\begin{array}{l}\text { Total } \\
\chi 2=33.219, \mathrm{df}=2, p=0.178\end{array}$ & 229 & 61.9 & 141 & 38.1 & 370 & 100.0 \\
\hline
\end{tabular}

The findings revealed that $64.3 \%$ of contraceptive users were in a monogamous union, while $35.7 \%$ were in polygamous unions. Chi-square results $(\chi 2=33.219, \mathrm{df}=2, p=0.178)$ established that polygyny was not significantly related to male contraceptive uptake at $\mathrm{p} \leq 0.05$. The null hypothesis was accepted and the alternate rejected. A conclusion was drawn that male contraceptive uptake was not significantly related to the number of wives a respondent had.

\section{Contraceptive Uptake by Family Size}

Ho5: Contraceptive uptake is not significantly related to family size at $p \leq 0.05$.

Chi-square statistic was performed on the null hypothesis and the outcome is shown in Table 5. 
Table 5: Chi-square results for contraceptive uptake and family size

\begin{tabular}{|c|c|c|c|c|c|c|c|c|}
\hline \multirow[t]{3}{*}{ Contraceptive uptake status } & \multicolumn{8}{|c|}{ Number of children $(n=572)$} \\
\hline & \multicolumn{2}{|c|}{ None } & \multicolumn{2}{|c|}{ 1-3 children } & \multicolumn{2}{|c|}{4 or more children } & \multicolumn{2}{|c|}{ Total } \\
\hline & $\bar{n}$ & $(\%)$ & $\mathbf{n}$ & $(\%)$ & n & $(\%)$ & n & $(\%)$ \\
\hline Contraceptive Users & 52 & 16.0 & 214 & 65.8 & 59 & 18.2 & 325 & 56.8 \\
\hline Contraceptive non-Users & 36 & 14.6 & 67 & 27.1 & 144 & 58.3 & 247 & 43.2 \\
\hline $\begin{array}{l}\text { Total } \\
\chi_{2}=11.878, \mathrm{df}=3, p=0.021\end{array}$ & 88 & 15.4 & 281 & 49.1 & 203 & 35.5 & 572 & 100.0 \\
\hline
\end{tabular}

Results in Table 5 revealed that $65.8 \%$ of contraceptive users had 1-3 children, $18.2 \%$ had four or more children and $16.0 \%$ had no children. The Chi-square results $(\chi 2=11.878, \mathrm{df}=3, p=0.021)$ established that family size as indicated by the number of children was significantly related to contraceptive uptake at $p \leq 0.05$. The null hypothesis was rejected and alternate retained. A conclusion was drawn that contraceptive uptake was significantly related to desired family size. These findings implied that the respondents with smaller families had higher levels of contraceptive uptake than those with larger families.

\section{Men's Contraceptive Uptake by Educational Attainment}

Ho6: Contraceptive uptake is not significantly related to educational attainment at $p \leq 0.05$.

Chi-square statistic was performed on the null hypothesis and the outcome is shown in Table 6.

Table 6: Chi-square results for contraceptive uptake by education attainment

\begin{tabular}{|c|c|c|c|c|c|c|c|c|c|c|}
\hline \multirow{3}{*}{$\begin{array}{l}\text { Contraceptive } \\
\text { status }\end{array}$} & \multirow{2}{*}{\multicolumn{2}{|c|}{$\begin{array}{l}\text { Educational A } \\
\text { No } \\
\text { education }\end{array}$}} & \multirow{2}{*}{\multicolumn{2}{|c|}{$\begin{array}{c}\text { Attainment }(\mathrm{n}=572 \\
\text { formalPrimary } \\
\text { School }\end{array}$}} & \multirow{2}{*}{\multicolumn{3}{|c|}{$\begin{array}{l}\text { High Tertiary } \\
\text { School }\end{array}$}} & \multirow{2}{*}{\multicolumn{3}{|c|}{ Total }} \\
\hline & & & & & & & & & & \\
\hline & $\bar{n}$ & $(\%)$ & $\mathbf{n}$ & $(\%)$ & n & $(\%)$ & $\mathbf{n}$ & $(\%)$ & $\mathbf{n}$ & $(\%)$ \\
\hline Contraceptive Users & 13 & 4.0 & 84 & 25.8 & 88 & 27.4 & 139 & 42.8 & 325 & 56.8 \\
\hline Contraceptive non-Users & 40 & 16.2 & 115 & 46.6 & 62 & 25.1 & 30 & 12.1 & 247 & 43.2 \\
\hline $\begin{array}{l}\text { Total } \\
\chi 2=84.770, \mathrm{df}=4, p=0.0\end{array}$ & 53 & 9.3 & 195 & 35.7 & 150 & 25.5 & 169 & 29.5 & 572 & 100.0 \\
\hline
\end{tabular}

Research findings revealed that $42.8 \%$ of respondents who had attained tertiary education had the highest proportion of contraceptive uptake, followed by those with high school education at $27.4 \%$, those with primary education at $25.8 \%$ and lastly, those with no formal education at $4.0 \%$.

The Chi-square results $(\chi 2=84.770, \mathrm{df}=4, p=0.001)$ established that education attainment was significantly related to contraceptive uptake at $\mathrm{p} \leq$ 0.05 . The null hypothesis was rejected and alternate retained. A conclusion was drawn that contraceptive uptake was significantly related to educational attainment. These findings implied that the respondents with higher educational achievement had higher levels of contraceptive uptake than those with less education or no formal schooling.

\section{Male Contraceptive Uptake by Employment Status}

Ho7: Contraceptive uptake is not significantly related to employment Status at $p \leq 0.05$.

A Chi-square test was performed on the null hypothesis and results of contraceptive uptake by respondents' working status are shown in Table 7. 
Table 7: Chi-square results of Contraceptive Uptake by employment status

\begin{tabular}{|c|c|c|c|c|c|c|}
\hline \multirow[t]{3}{*}{ Contraceptive uptake status } & \multicolumn{6}{|c|}{ Employment Status $(n=572)$} \\
\hline & \multicolumn{2}{|c|}{ Wage-earners } & \multicolumn{2}{|c|}{ Unemployed } & \multicolumn{2}{|c|}{ Total } \\
\hline & $\mathbf{N}$ & $(\%)$ & n & $(\%)$ & n & $(\%)$ \\
\hline Contraceptive Users & 286 & 88.0 & 39 & 12.0 & 325 & 56.8 \\
\hline Contraceptive non-Users & 156 & 63.2 & 91 & 36.8 & 247 & 43.2 \\
\hline $\begin{array}{l}\text { Total } \\
\chi 2=52.463, \mathrm{df}=2, p=0.172\end{array}$ & 442 & 77.3 & 130 & 22.7 & 572 & 100.0 \\
\hline
\end{tabular}

Results in Table 7 showed that $88.0 \%$ of wage earners used contraceptives compared to $12 \%$ of unemployed respondents. The Chi-square results $(\chi 2=52.463, \mathrm{df}=2, p=0.172)$ determined that employment status was not significantly related to contraceptive uptake. The null hypothesis was accepted and the alternate was rejected. A conclusion was drawn that contraceptive uptake was not significantly related to wage-earning at $\mathrm{p} \leq 0.05$.

\section{Male Contraceptive Uptake by Level of Income}

Ho8: Contraceptive uptake is not significantly related to income level at $p \leq 0.05$.

Chi-square test results between respondents' contraceptive uptake and level of income are shown in Table 8.

Table 8: Chi-square results for contraceptive uptake by income

\begin{tabular}{|c|c|c|c|c|c|c|c|c|c|c|}
\hline \multirow{3}{*}{$\begin{array}{l}\text { Contraceptive } \\
\text { status }\end{array}$} & \multicolumn{10}{|c|}{ Level of income (KES.) $(n=442)$} \\
\hline & \multicolumn{2}{|c|}{$<\mathbf{1 0 , 0 0 0}$} & \multicolumn{2}{|c|}{$10,001-20,000$} & \multicolumn{2}{|c|}{$\begin{array}{l}20,001- \\
30,000\end{array}$} & \multicolumn{2}{|c|}{$>30,000$} & \multicolumn{2}{|c|}{ Total } \\
\hline & $\mathbf{n}$ & $\%$ & $\mathbf{N}$ & $\%$ & $\mathbf{N}$ & $\%$ & $\mathbf{N}$ & $\%$ & $\mathbf{N}$ & $\%$ \\
\hline Contraceptive Users & 15 & 5.3 & 169 & 59.7 & 68 & 24 & 31 & 11 & 283 & 64 \\
\hline Contraceptive Non-Users & 74 & 46.5 & 62 & 39 & 14 & 8.8 & 9 & 5.7 & 159 & 36 \\
\hline $\begin{array}{l}\text { Total } \\
\chi 2=23.334, \mathrm{df}=4, \mathrm{p}=0.032\end{array}$ & 89 & 20.1 & 231 & 52.3 & 82 & 18.6 & 40 & 9 & 442 & 100 \\
\hline
\end{tabular}

The results in Table 8 show that $59.7 \%$ of the respondents using contraceptives were in the income bracket of Ksh. 10,001-20,000 compared to $24.0 \%$ who were in the income bracket of Ksh. 20,001-30,000, 11.0\% who earned more than Ksh. 30,000 and $5.3 \%$ whose income was less than Ksh. 10,000. Respondents within the income bracket of Ksh. 10,001-20,000 had a higher contraceptive uptake compared to those who earned less than Ksh. 10,000, more than Ksh. 30,000 and Ksh. 20,00130,000 respectively. The Chi-square results $(\chi 2=23.334, \mathrm{df}=4, p=0.032)$ established that level of income was significantly related to contraceptive uptake among respondents at $\mathrm{p} \leq 0.05$. The null hypothesis was rejected and alternate retained. A conclusion was drawn that contraceptive uptake was significantly related to the level of income. These findings implied that middle-aged males had higher levels of contraceptive uptake than younger counterparts.

\section{DISCUSSION}

This research established that male contraceptive uptake was significantly related to age, education attainment, income level, marital status, desired family size attainment, and location of residence.

\section{Male Contraceptive Uptake and Age}

The study established that male contraceptive uptake was lowest among teenage males aged 18-19 years, reached a peak among men in their twenties (21-29 years) and thirties (30-39 years) and then declined among older men (40 years and above). The high contraceptive uptake among men in the 21-39-year age bracket was attributed to a strong desire for childbearing among young couples and a high growing interest in birth spacing. This finding concurs with the KDHS (2014) report that younger men use contraceptives for birth spacing and for 
limiting the number of births. This research is supported by Bietsch (2015), who reported that the low contraceptive prevalence among teenage men under 20 years is because they are the least likely to be married or to have children or to ever have used contraception before. A study by Palamuleni (2013) established that there was low contraceptive prevalence among men aged 15-19 years which may be attributed to the fact that most of these males were single or newly married, and marriage is looked upon as an institution of childbearing. According to (Wilson, Ngige \& Trollinger, 2003), fertility is central to Kenyan marriage and childbearing serves as evidence of reproductive capability. Contraception is therefore considered a contradiction to the primary purpose of marriage. According to Njue, Rombo and Ngige (2007), the average age at first marriage for males in Kenya is 25 years. Therefore, young men would not consider birth spacing or birth limiting during their early stages of family formation. Kasongo (2013) reported that contraceptive uptake declines among older couples who have attained the optimum family size.

\section{Male Contraceptive Uptake and Marital Status}

The study established that male contraceptive uptake was highest among married men in a monogamous union. This finding implied that married males used contraception to space and limit births. This finding concurs with the KDHS (2014) report that married men were more likely to use contraceptives for birth spacing and for limiting the number of births once they had achieved the desired family size. This study concurs with Ngige, Ondigi and Wilson (2008), who reported that contemporary young, educated men prefer a monogamous marriage and fewer children compared to older men who prefer a polygamous marriage with large families.

\section{Male Contraceptive Uptake and Desired Number of Children}

The research established that male contraceptive uptake was associated with the number of children and desired family size. The majority of respondents had a desired family size of three children. This finding concurs with a study by Kasongo (2013), which reported that married couples were more likely to practice modern contraception when they already had attained the desired number of children. This study is also supported by Mwito (2017), who reported that contraceptive uptake increases with parity in Kenya. This implies that the higher the number of children, the higher the prevalence of male contraceptive uptake. Similar studies in Malawi have shown that the number of children influences the uptake of contraception (Palamuleni, 2013).

\section{Male Contraceptive Uptake and Educational Attainment}

The research determined that male contraceptive uptake was associated with educational attainment. The higher the level of formal education, the higher the prevalence of male contraceptive uptake. This finding concurs with Wilson \& Ngige (2006) report that male contraceptive uptake was associated with higher levels of educational attainment. On the contrary, males with no formal education were less likely to use contraceptives to limit or space births. This finding concurs with studies by Mwito (2017) and Kamau (2007), which reported that the more highly educated males have more information and access to contraceptives compared to their least educated counterparts. Furthermore, men with no formal education were less likely to use contraceptives compared to those who had completed high school and college education.

\section{Male Contraceptive Uptake and Level of Income}

The results showed that there was a significant positive linear relationship between the level of income and male contraception. The higher the income bracket, the higher the uptake of contraception and vice versa. Men are cognizant of the fact that the larger the family size, the higher the cost of raising one's family. There is therefore need for spacing and limiting births through contraception. This finding is supported by previous research by Yidana, Ziblim, Azongo and Abass (2015), who established that level of income has a direct positive influence on male contraceptive uptake. This finding is sustained by the KDHS (2014) report that there is an increased prevalence of contraceptive uptake among males with higher socioeconomic status compared to their 
counterparts in the lower socioeconomic class. This finding also concurs with previous research by Kisa, Zeyneloğlu and Delibas (2013), and Anasel and Mlinga (2014), which established that there is a significant relationship between the level of income and contraceptive uptake.

\section{Male Contraceptive Uptake and Location of Residence}

This study established that location of residence had a significant relationship with male contraceptive uptake. Men residing in urban areas were more likely to use contraception than their counterparts residing in rural areas. These findings are supported by Ngige, Ondigi and Wilson (2008), which established that urbanisation is associated with the shift from the traditional large extended family structure in a rural setting to the contemporary smaller nuclear family structure in urban areas. The research also found that HIV infection among males in urban areas is almost twice compared to their rural counterparts. Therefore, there is an increased use of condoms by males in an effort to reduce HIV infection as well as for contraception. These findings concur with previous research by Gilbert and Bernard (2015), who showed that male contraceptive uptake is higher among men residing in urban areas than among men residing in rural areas in Sub-Saharan Africa. The study found out that differences in the availability of related social services such as education, access to family planning and health care services can be attributed to the observed variation in contraceptive use by location of residence.

\section{CONCLUSION}

The study concluded that male contraceptive uptake was significantly related to age, education attainment, income level, marital status, monogamous unions, attainment of desired family size and location of residence. The findings established that younger males, who were more highly educated, with regular and higher incomes, whose marriages were monogamous, who had attained the optimum family size and lived in an urban setting achieved better contraceptive uptake than their older, less educated males who were in a polygamous union and resided in a traditional rural setting. In order to achieve sustainable family planning targets, it is critical to involve the male partners in contraceptive education and uptake. It is recommended that there is a need to develop innovative, male-friendly and acceptable contraceptive options for men besides condoms and vasectomy, with the view of increasing contraceptive uptake among males in Kenya.

\section{ACKNOWLEDGEMENTS}

We wish to appreciate the support of the respondents who participated in this research.

\section{REFERENCES}

Anasel, M. G., \& Mlinga, U. J. (2014). Determinants of contraceptive use among married women in Tanzania: Policy implication. Etude de La Population Africaine, 28(2), 978988.

Bietsch, K. E. (2015). Men's Attitudes towards Contraception in Sub-Saharan Africa. African Journal of Reproductive Health, 19(3), 41-54. Retrieved from http://www.ncbi.nlm.nih.gov/pu bmed/26897912

Gilbert, O., \& Bernard, N. (2015). Influence of women factors on modern contraceptive usage among currently married women in Malawi. Research on Humanities and Social Sciences, 5(10), 156-164.

Guttmacher Institute. (2021). Contraceptive use in the United States by method. Fact Sheet, May 2021. New York, NY. https://www.guttmacher. org.

Kamau, J. N. (2007). Factors associated with reproductive behaviour of low-income mothers in Kiandutu Slum in Thika District, Kenya. Masters' Thesis, Kenyatta University. Retrieved from http://ir- library.ku.ac.ke/handle/12345678 9/15083.

Kasongo, D. Y. (2013). Spouses' Socioeconomic Characteristics and Contraceptive Use in Kinshasa, Zaire. African Population Studies 8, 58-72. http://doi.org/10.11564/8=0=416.

Kisa, S., Zeyneloğlu, S., \& Delibaş, L. (2013). Influence of age on the usage of family planning 
methods by Turkish married men living in south eastern Turkey. Turkish Journal of Medical Sciences, 43(5), 756- 763. http://doi.org/10.39 06/sag-1209-73

Matlala, S. F., \& Mpolokeng, M. B. L. (2010). Knowledge, attitudes and practices of rural men towards the use of contraceptives in GaSekororo, Limpopo Province, South Africa. Professional Nursing Today, 14(2), 3944.

Mwito, A. M. (2017). Influence of men's perceptions on contraceptive uptake in Maua Division, Meru County, Kenya. Masters Thesis. Kenyatta University.

Ngige, L. W., Ondigi, A. N., \& Wilson, S. M. (2008). Family diversity in Kenya. In C.B. Hennon \& S.M. Wilson (Eds.). Families in a global context (pp. 207-231). New York: Routledge.

Njue, J. R. M., Rombo, D. O., \& Ngige, L. W. (2007). Family strengths and challenges in Kenya. Marriage \& Family Review, 41(1-2), 4770 .

Odu, O. O., Ijadunola, K. T., Komolafe, J. O., \& Adebimpe, W. T. (2006). Men's knowledge of and attitude with respect to family planning in a sub-urban Nigerian community. Nigerian Journal of Medicine, 15(3), 260-265.

Orodho, J. A. (2008). Techniques of writing research proposal and reports in education and social sciences. Maseno: Kanezja.

Palamuleni, M. E. (2014). Demographic and Socioeconomic factors affecting contraceptive use in Malawi. Journal of Human Ecology, 46(3), 331-341.

Shattuck, D., Kerner, B., Gilles, K., Hartmann, M., Ng'ombe, T., \& Guest, G. (2011). Encouraging contraceptive uptake by motivating men to communicate about family planning: the Malawi Male Motivator project. American Journal of Public Health, 101(6), 1089- 1095.http://doi.org /10.4314/ajrh.v17i3.
United Nations (2021). World contraceptive use. Retrieved from https://www.un.org/developmen t/desa/pd/data/world-contraceptive-use.

Wilson, S. M. \& Ngige, L. W. (2006). Families in Sub-Saharan Africa. In B.B. Ingoldsby \& S.D. Smith (Eds.). Families in global and multicultural perspective. (pp. 247-273). Thousand Oaks, CA: Sage.

Wilson, S. M., Ngige, L. W., \& Trollinger, L. J. (2003). Connecting generations: Kamba and Maasai paths to marriage in Kenya. In R.R. Hamon \& B.B. Ingolsby (Eds.). Mate selection across cultures. (pp. 95-118). Thousand Oaks, CA: Sage.

World Health Organization. (2020). Family planning/contraception Methods. Retrieved from http://www.who.int/mediacentre/factsheet s/fs351/en/

Yidana, A., Ziblim, S. D., Azongo, T. B., \& Abass, Y. I. (2015). Socio-cultural determinants of contraceptives use among adolescents in Northern Ghana. Public Health Research, 5, 8389. 